\title{
A Systematised Review of Primary School Whole Class Child Obesity Interventions: Effectiveness, Characteristics, and Strategies
}

\author{
Elise C. Brown, ${ }^{1}$ Duncan S. Buchan, ${ }^{2}$ Julien S. Baker, ${ }^{2}$ Frank B. Wyatt, ${ }^{3}$ \\ Danilo S. Bocalini, ${ }^{4}$ and Lon Kilgore ${ }^{5}$ \\ ${ }^{1}$ Department of Wellness, Health Promotion and Injury Prevention, School of Health Sciences, Oakland University, \\ 2200 N. Squirrel Road, Rochester, MI 48309-4452, USA \\ ${ }^{2}$ Institute for Clinical Exercise \& Health Science, University of the West of Scotland, Almada Street, Hamilton ML3 0JB, UK \\ ${ }^{3}$ Department of Exercise Physiology \& Athletic Training, Midwestern State University, Wichita Falls, TX 76308, USA \\ ${ }^{4}$ Translational Physiology Laboratory and Post Graduate Program in Physical Education and Aging Science, \\ São Judas Tadeu University (USJT), 05503-001 São Paulo, SP, Brazil \\ ${ }^{5}$ Kilgore Academy, 816 Keli Court, Azle, TX 76020, USA
}

Correspondence should be addressed to Elise C. Brown; elisebrown@oakland.edu

Received 1 April 2016; Accepted 26 June 2016

Academic Editor: Alberto Raggi

Copyright (C) 2016 Elise C. Brown et al. This is an open access article distributed under the Creative Commons Attribution License, which permits unrestricted use, distribution, and reproduction in any medium, provided the original work is properly cited.

Background. A systematised review was conducted to examine the effectiveness of school-based interventions that focus on changing dietary intake and physical activity levels to reduce childhood obesity. Methods. Multiple databases were searched for randomised and nonrandomised interventions from 2007 to 2016 in full-time elementary schools, which were delivered to the whole class, included dietary and physical activity components, involved both sexes, were written in English, and used body mass index (BMI) as an outcome. Results. The database search produced 8,866 titles from which 78 were deemed relevant and assessed for inclusion resulting in 15 studies meeting all inclusion criteria. From these 15 studies, 9 yielded a reduction or stabilisation in BMI or BMI $z$-score in the entire intervention group and/or subgroups. Programmes lasting between 6 and 12 months that involve multiple environmental, educational, and physical strategies appear to be most likely to result in BMI or BMI $z$-score improvement. Moderators most likely influencing an improvement in BMI included increased physical activity, decreased sugar sweetened beverages intake, and increased fruit intake. Conclusions. School-based interventions may be an effective means for child obesity prevention. The identification of consistent elements used in school-based interventions that have demonstrated effectiveness may aid in preventing child obesity.

\section{Introduction}

From 1980 to 2013, child obesity prevalence increased by $47.1 \%$ globally [1]. The elevated prevalence rates are concerning because of the associated increased risk of obese children developing dyslipidemia, hypertension, and insulin resistance compared to normal weight children [2]. Additionally, when child obesity continues into adulthood the individual is at greater risk of health complications [3]. When estimating incidence of child obesity, children are often classified as obese based on body mass index (BMI) percentile cut-offs from growth references [4-7]. BMI and BMI standard deviation scores (BMI-SDS) or $z$-scores are primary methods for governments $[7,8]$ and international health organisations $[5,6]$ to classify children as obese. BMI is also the most commonly used obesity indicator for clinical and research purposes [9].

Although it has been recognized that schools are ideal settings for obesity prevention initiatives [10], systematic reviews and meta-analyses have demonstrated mixed results in terms of the effectiveness of school-based child obesity treatment and prevention interventions [11-14]. Hung and 
colleagues concluded that school-based interventions have not been effective in improving BMI [13]. On the other hand, Lavelle and colleagues reported that school-based interventions are effective in reducing BMI [14], and Gonzalez-Suarez concluded that school-based interventions are effective in the short-term at obesity prevention [12]. However, each of these studies included universal interventions (delivered to the whole class) as well as interventions delivered specifically to obese children. Interventions including only obese children are likely to bias components towards treatment rather than combining prevention and treatment strategies typical to universal approaches [14], and these types of interventions may need to be assessed separately. Brown and Summerbell only included universal studies and concluded that physical activity (PA) interventions may be an effective means for overweight prevention [11]. Although this review focused solely on universal interventions, only interventions up to the year 2007 were included in the study. Therefore, an updated review including only universal interventions is needed. The primary aim of this review is to assess the effects of universal, school-based interventions with healthy eating (HE) and PA components for the prevention and treatment of obesity in primary school children. A secondary aim is to identify intervention characteristics and moderators that may contribute to effectiveness.

\section{Materials and Methods}

The inclusion criteria for systematic reviews such as Cochrane reviews are driven by the participants, interventions, and clinical questions being asked [15]. The use of another method of qualitative reviews, systematised reviews, was chosen for this focused approach requiring the outcome measure to be part of the inclusion criteria. In order to maintain quality and reduce bias [16], all processes were described in detail and quality assessment of included studies was conducted. PRISMA guidelines were used for the reporting procedures [17].

2.1. Literature Search. A literature search was conducted in PubMed, Health Source, MEDLINE, PsycBOOKS, Psychology and Behavioural Sciences Collection, PsycINFO, SocINDEX, and SPORTDiscus in the years 2007-2016. Various search terms were used including "child overweight," "child obesity," "physical activity," "nutrition," "health education," "BMI," "BMI $z$-score," "BMI-SDS," and "school intervention," and the search was limited to peer-reviewed journal articles. Also, reviews and meta-analyses were crossreferenced to identify additional studies that were not previously captured.

2.2. Inclusion Criteria. Given the widespread use and the impact that BMI may have on government policy [18], a focused approach was taken which limited the outcome variables to BMI and BMI-SDS/ $z$-score. From this point forward, BMI and BMI-SDS/ $z$-score will be referred to as BMI unless BMI-SDS/z-score is specified. Studies selected for inclusion were school-based, universal initiatives which aimed to improve BMI and included PA and HE components. Studies must have included BMI in pre- and postanalyses. Articles examining changes in obesity prevalence without providing BMI changes were not included. Since participants who attend after-school lifestyle programmes may have different characteristics compared to those who do not, such as higher PA levels [19], exclusively after-school studies were excluded. Interventions must have had HE and PA component during school hours. Studies that met these criteria but additionally had after-school PA programmes were also included. Participants included boys and girls of any nationality in full-time elementary schools. Studies must have been written in English. Study designs included randomised controlled trials (RCTs) and nonrandomised controlled trials (NRCTs) with no-intervention controls. Studies including multiple treatment groups without a control group were excluded.

\subsection{Intervention Characteristics. Intervention duration was} classified as short-term ( $\leq 6$ months), moderate-term $(>6$ months and $\leq 12$ months), or long-term (>12 months) [20]. Studies were classified as teacher-led if the intervention was delivered by classroom or physical education teachers or if the teacher collaborated with other professionals or students [21]. If no parental involvement was described, the study was classified as no parental involvement [13]. Studies were classified as no theoretical framework if there was no mention of the use of a behaviour change theory or theoretical framework [22]. Intervention types were classified as educational intervention, environmental intervention, physical intervention, or a combination of the three [14].

2.4. Outcome Measures. Primary outcomes investigated to determine intervention success included BMI and/or BMI$\mathrm{SDS} / z$-score. In line with Demetriou and Höner's review, intervention success was defined as a reduction in BMI for the intervention group when compared with the control group or no change in BMI for the intervention group when compared to an increase in the control group [23]. Other outcomes such as no significant changes in BMI for the intervention and control group were labelled as no change.

2.5. Moderator Variables. Behavioural moderators included PA, fruit intake, vegetable intake, sedentary time, screen time (including TV viewing time only), and sugar sweetened beverage (SSB) intake. Multiple articles relating to the same study were included if relative outcomes were published separately.

2.6. Study Quality. To determine the validity and quality of individual studies, Downs and Black's validated tool for assessing the methodological quality of randomised and nonrandomised studies of health care interventions was used [24]. Subscales of the tool examined reporting, external validity, internal validity bias, selection bias, and power. Item 27 of the tool assessed power and had 6 possible scores based on the sample size. In line with Marquet and colleagues, scoring for item 27 was simplified so that a score of one was 
given if sufficient statistical power was achieved and a score of zero was given if sufficient power was not achieved [25]. The tool included a total of 27 items, and items were scored one or zero with a higher score indicative of higher quality. See the following list for criteria used. In accordance with HaiBo and colleagues, if studies received a score of one on at least $50 \%$ of the items then they were deemed sufficient in quality and were included in the review [26].

Criteria for assessing study quality and bias are as follows:

Reporting: it included the following points:

(1) Is the hypothesis/aim/objective of the study clearly described?

(2) Are the main outcomes to be measured clearly described in the introduction or methods section?

(3) Are the characteristics of the schools/students included in the study clearly described?

(4) Are the interventions of interest clearly described?

(5) Are the distributions of principal confounders in each group of subjects to be compared clearly described?

(6) Are the main findings of the study clearly described?

(7) Does the study provide estimates of the random variability in the data for the main outcomes?

(8) Have all important adverse events that may be a consequence of the intervention been reported?

(9) Have the characteristics of patients lost to follow-up been described?

(10) Have actual probability values been reported for main outcomes except where the probability value is $<0.001$ ?

External validity: it included the following points:

(11) Were the subjects asked to participate in the study representative of the entire population from which they were recruited?

(12) Were those subjects who were prepared to participate representative of the entire population from which they were recruited?

(13) Were the staff, places, and facilities, where the patients were treated, representative of the treatment the majority of patients receive?

Internal validity-bias included the following points:

(14) Was an attempt made to blind study subjects to the intervention they have received?

(15) Was an attempt made to blind those measuring the main outcomes of the intervention?

(16) If any of the results of the study were based on "data dredging," was this made clear?
(17) In trials and cohort studies, do the analyses adjust for different lengths of follow-up of patients, or, in case-control studies, is the time period between the intervention and outcome the same for cases and controls?

(18) Were the statistical tests used to assess the main outcomes appropriate?

(19) Was compliance with the interventions reliable?

(20) Were the main outcome measures used accurate (valid and reliable)?

Internal validity-confounding (selection bias) included the following points:

(21) Were the patients in different intervention groups (trials and cohort studies) or were the cases and controls (case-control studies) recruited from the same population?

(22) Were study subjects in different intervention groups (trials and cohort studies) or were the cases and controls (case-control studies) recruited over the same period of time?

(23) Were study subjects randomised to intervention groups?

(24) Was the randomised intervention assignment concealed from both patients and health care staff until recruitment was complete and irrevocable?

(25) Was there adequate adjustment for confounding in the analyses from which the main findings were drawn?

(26) Were losses of patients to follow-up taken into account?

Power: it included the following:

(27) Did the study have sufficient power to detect a clinically important effect where the probability value for a difference being due to chance is less than $5 \%$ ?

2.7. Analysis Plan. A qualitative analysis of the findings was conducted. Similar to Golley and colleagues approach [27], a behavioural variable was classified as a potential moderator if a significant change in the variable occurred in addition to a significant change in BMI in the intervention compared to the control group. The frequency of intervention effectiveness by moderator variable was determined. Data was extracted by one reviewer and summarized from each article. The extracted data included intervention length, delivery personnel, theoretical framework, study design, strategies, components, and outcomes. The results were presented in narrative form.

\section{Results}

See Figure 1 for a description of study selection and processing. Fifteen studies met the inclusion criteria and were synthesized in this review. Additionally, 2 other studies [28, 29] 


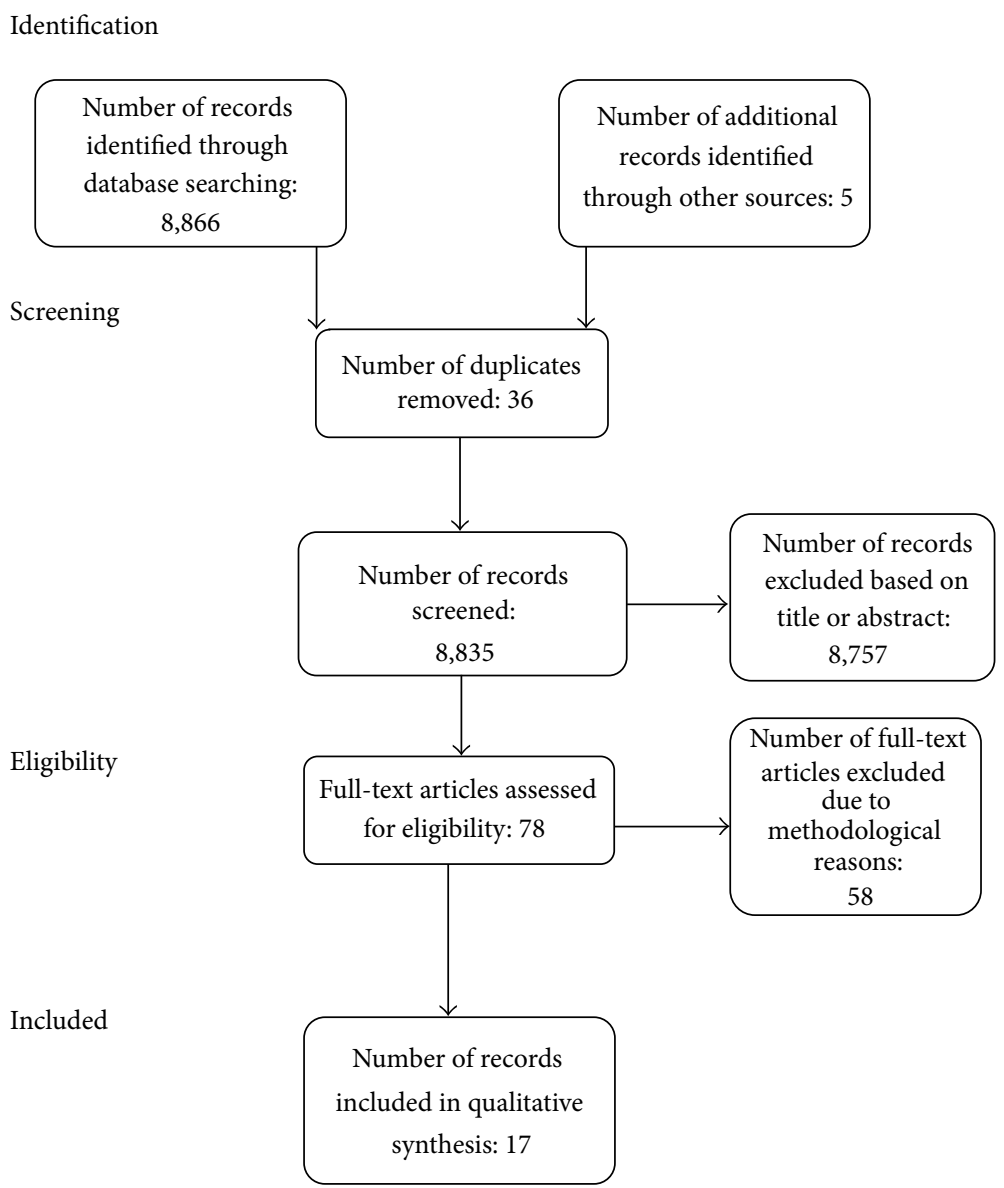

FIGURE 1: PRISMA flow diagram of processes for study inclusion.

were included as they related to one specific intervention [30] that met all inclusion criteria and elaborated on moderators. In total, 17 studies were included.

3.1. Intervention Characteristics. Table 1 provides intervention methodologies, characteristics, strategies, and critical appraisal scores in alphabetical order of study location. From the included studies the sample sizes ranged from 294 to 2622 participants, and the intervention durations ranged from 5 to 36 months. Seven studies had intervention durations $>12$ months with five resulting in improved BMI [30-34], seven studies lasted between 6 and 12 months with four achieving intervention effectiveness [35-38], and one study's duration was < six months with no BMI improvement [39]. Eight studies utilized a behaviour change theory [30, 33, 35, 36, 39-42] with the Social Cognitive Theory (SCT) being the most frequently used. Four of these studies resulted in an improvement in BMI [30, 33, 35, 36]. Similarly, 5 of the 9 studies that did not include a behaviour change theory resulted in BMI improvement [31, 32, 34, 37, 38]. Most interventions were delivered solely by teachers, while some were delivered by teachers and an internet programme [34], teachers alongside exercise and nutrition specialists [43], and teachers and older students [38]. Seven of the twelve studies that included teachers-led interventions were effective [30, 33-38]. Non-teacher delivered interventions were delivered by community activity coordinators and undergraduate medical students, and one study only made environmental changes. Eleven studies included a parental involvement component. Although six of the eleven interventions including a parental component prevented a decrease in or improved BMI [30,31, 33, 35-37], three out of the four studies that did not include parental involvement also noted improvements in BMI $[32,34,38]$. Most studies used a combination of environmental, educational, physical activity, and parental involvement strategies, while four used only an educational strategy. Eight of the eleven studies that used a combination of strategies achieved effectiveness [30, 32-38], and one of the four that used only educational strategies was effective [31]. All studies met the criteria for methodological quality.

3.2. Primary Outcomes. Table 2 presents the primary and secondary variables and outcomes. Some studies reported BMI changes for subgroupings rather than the entire group. When looking at BMI in the total intervention group, six out of fourteen studies achieved an improvement [31-33, 35-37]. Nine out of fifteen studies resulted in an improvement in BMI in the total group or subgroupings [30-38]. In studies that analysed subgroupings, some reported that improvements in 


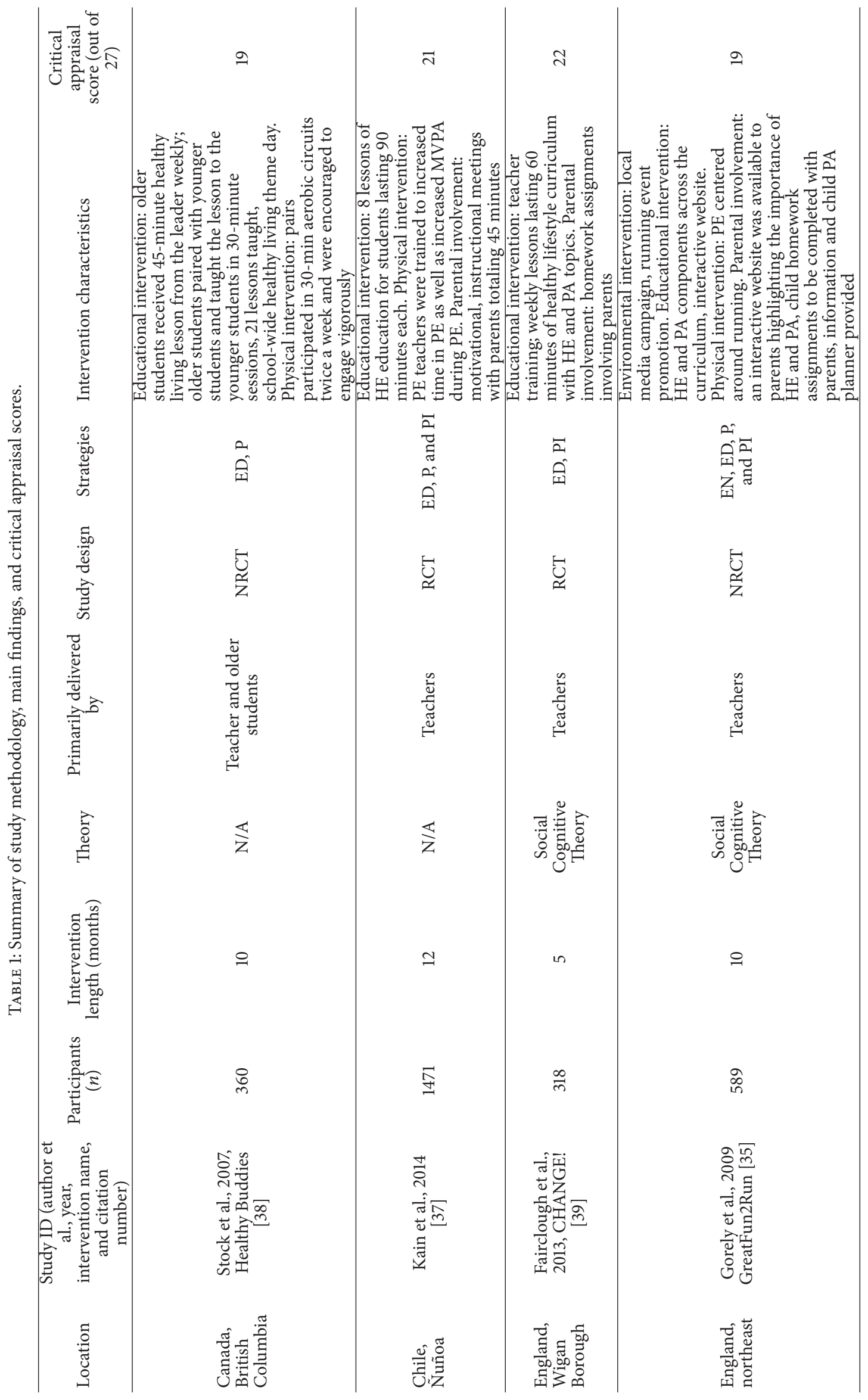




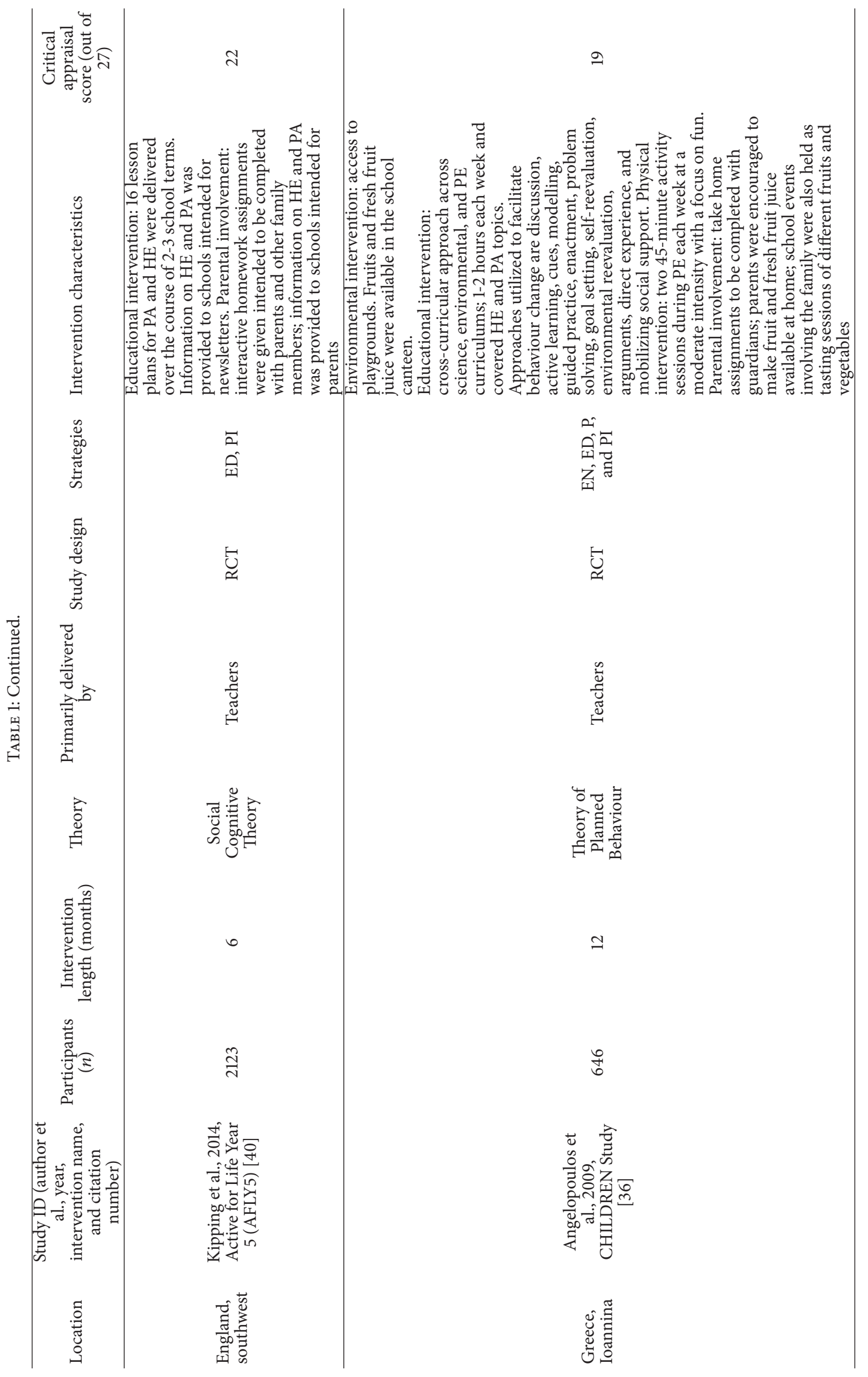




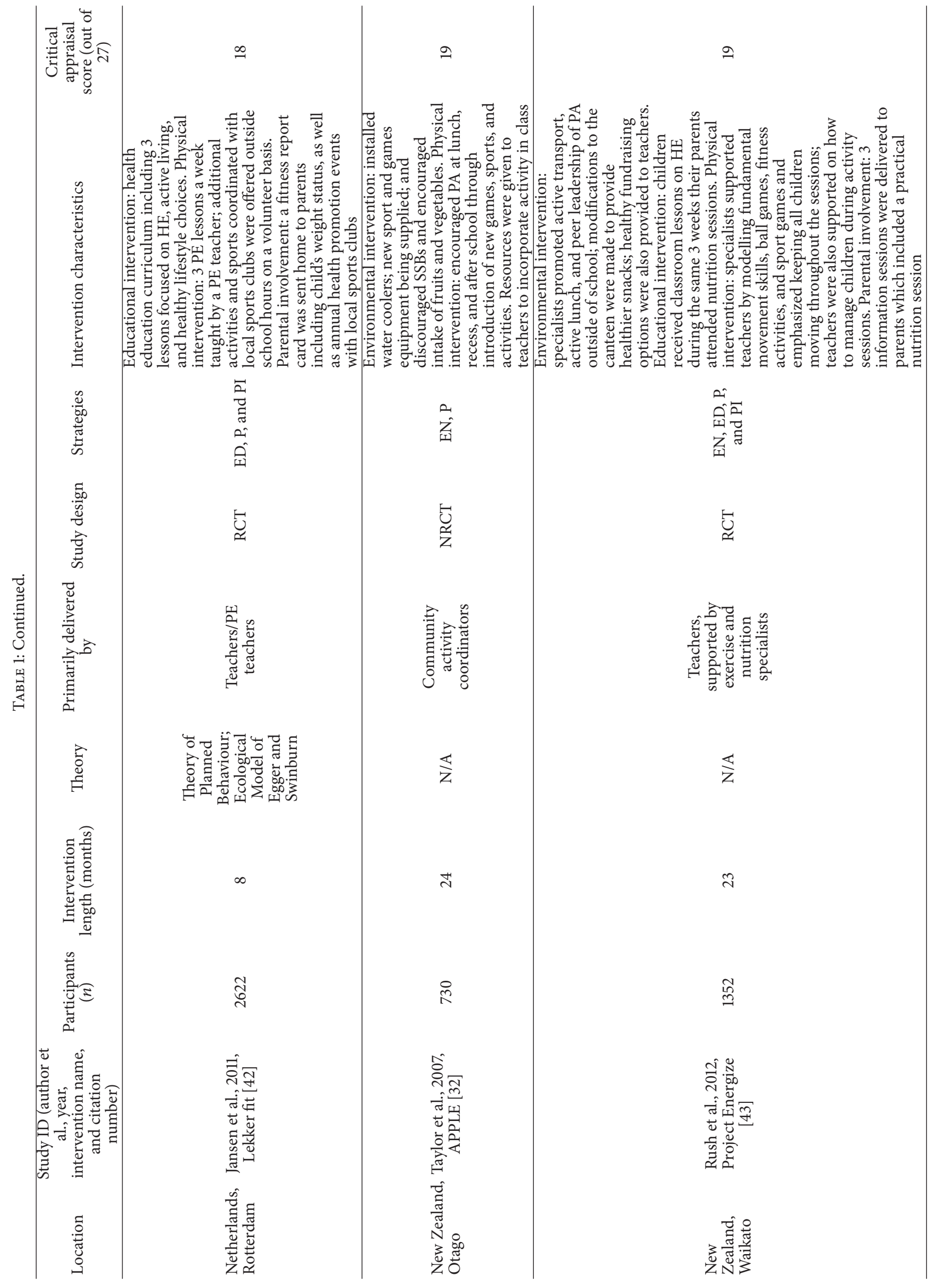




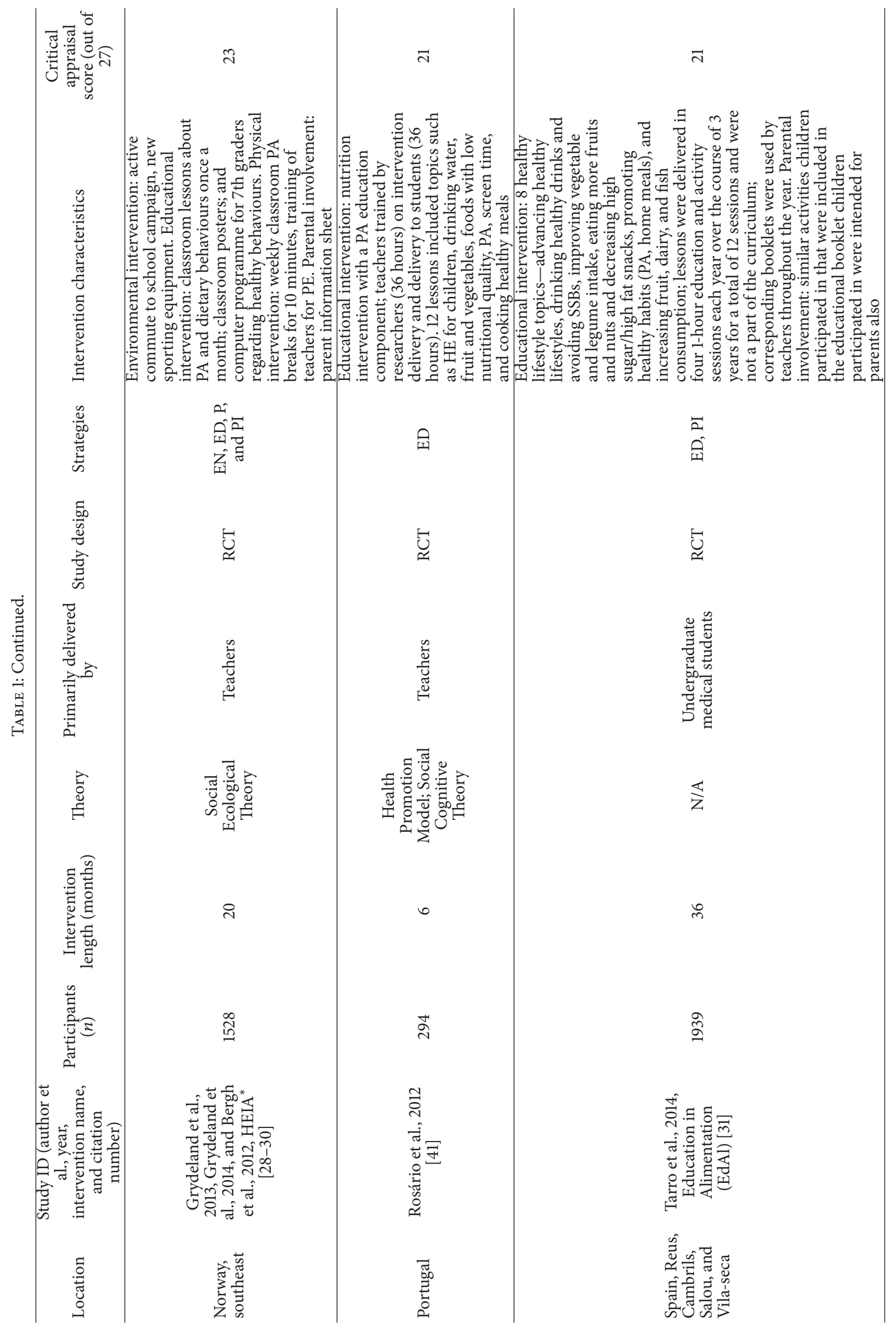




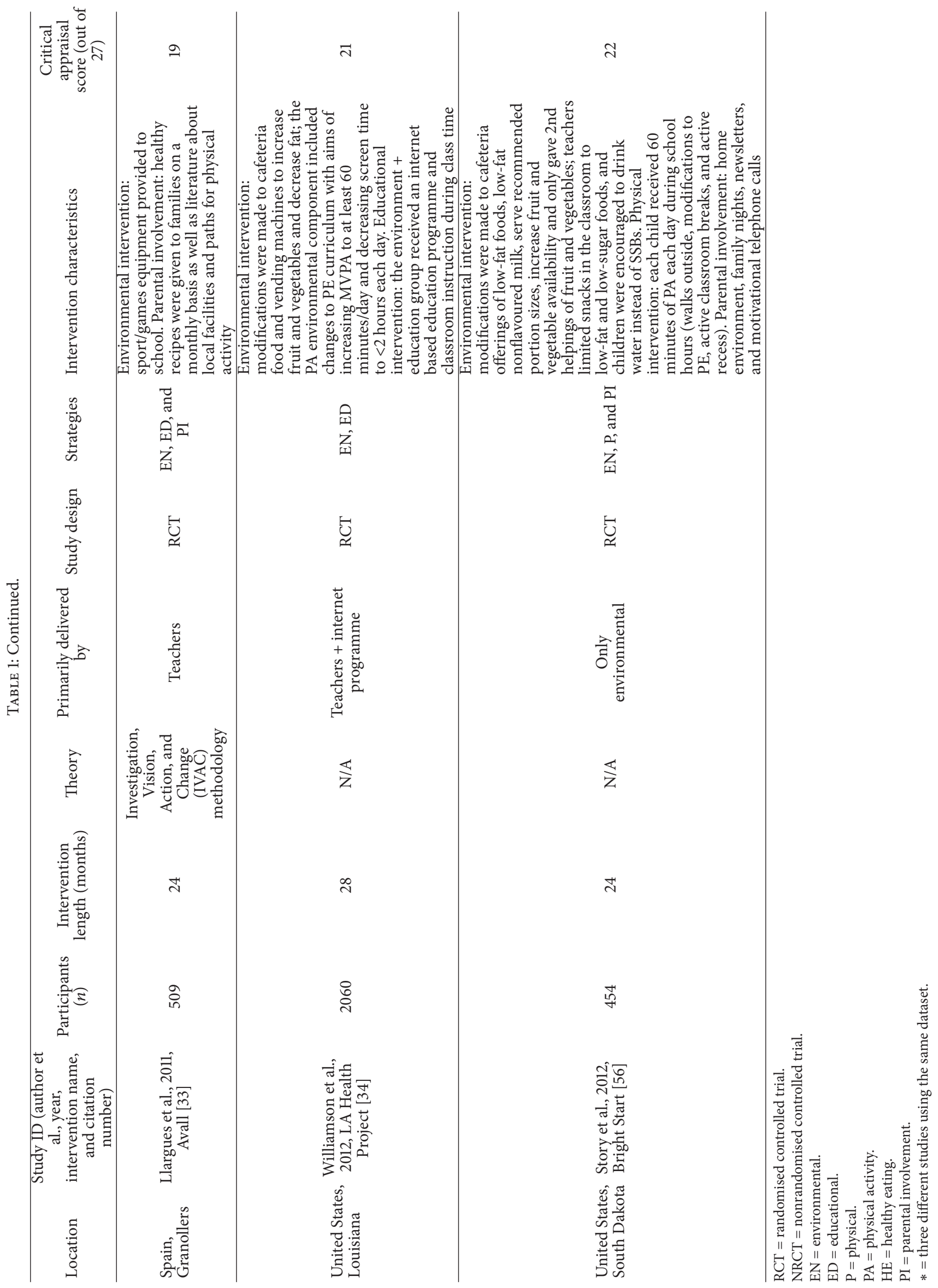


TABLE 2: Summary of primary outcomes and moderator variables.

\begin{tabular}{|c|c|c|c|c|c|}
\hline Location & $\begin{array}{l}\text { Study ID (author et } \\
\text { al., year, and } \\
\text { intervention name) }\end{array}$ & $\begin{array}{l}\text { Primary measures } \\
\text { (growth reference) }\end{array}$ & $\begin{array}{l}\text { Moderator } \\
\text { variables }\end{array}$ & Primary outcomes & Moderator outcomes \\
\hline $\begin{array}{l}\text { Canada, British } \\
\text { Columbia }\end{array}$ & $\begin{array}{l}\text { Stock et al., 2007, } \\
\text { Healthy Buddies } \\
{[38]}\end{array}$ & BMI & $\mathrm{X}$ & $\begin{array}{l}\text { Younger group: no } \\
\text { change; older group: } \\
\text { positive }\end{array}$ & $\mathrm{X}$ \\
\hline Chile, Ñuñoa & $\begin{array}{l}\text { Kain et al., } 2014 \\
{[37]}\end{array}$ & $\begin{array}{l}\text { BMI } z \text {-score } \\
(\mathrm{WHO})\end{array}$ & $\operatorname{MVPA}(\mathrm{p})$ & positive & Positive \\
\hline $\begin{array}{l}\text { England, Wigan } \\
\text { Borough }\end{array}$ & $\begin{array}{l}\text { Fairclough et al., } \\
\text { 2013, CHANGE! } \\
{[39]}\end{array}$ & $\begin{array}{l}\text { BMI, BMI } z \text {-score } \\
\text { (IOTF) }\end{array}$ & $\begin{array}{l}\text { PA and sedentary } \\
\text { time (a), dietary } \\
\text { intake ( } 24 \text {-hour } \\
\text { recall food intake } \\
\text { questionnaire) }\end{array}$ & $\begin{array}{l}\text { BMI, no change, BMI } \\
z \text {-score, no change }\end{array}$ & $\begin{array}{l}\text { Sedentary time, no change, } \\
\text { light PA, positive, moderate } \\
\text { PA, no change, vigorous } \\
\text { PA, no change, and fruit } \\
\text { and vegetable intake, no } \\
\text { change }\end{array}$ \\
\hline England, northeast & $\begin{array}{l}\text { Gorely et al., } 2009 \\
\text { GreatFun2Run [35] }\end{array}$ & $\begin{array}{l}\text { BMI, BMI-SDS } \\
\text { (UK 1990) }\end{array}$ & $\begin{array}{l}\text { PA }(a, p) \text {, fruit and } \\
\text { vegetable intake } \\
\text { (24-hour recall } \\
\text { with interview) }\end{array}$ & $\begin{array}{l}\text { BMI, positive, } \\
\text { BMI-SDS, positive }\end{array}$ & $\begin{array}{l}\text { MVPA, positive, fruit and } \\
\text { vegetable intake, no change }\end{array}$ \\
\hline England, southwest & $\begin{array}{l}\text { Kipping et al., 2014, } \\
\text { Active for Life Year } \\
5 \text { (AFLY5) [40] }\end{array}$ & BMI & $\begin{array}{l}\text { MVPA and } \\
\text { sedentary time (a), } \\
\text { screen time (q), } \\
\text { fruit and vegetable } \\
\text { consumption (q), } \\
\text { and high energy } \\
\text { drink intake (q) }\end{array}$ & No change & $\begin{array}{l}\text { Weekend screen time, } \\
\text { positive, high energy } \\
\text { drinks, positive, weekday } \\
\text { screen time, no change, } \\
\text { fruit and vegetable } \\
\text { consumption, no change, } \\
\text { MVPA, no change, and } \\
\text { sedentary time, no change }\end{array}$ \\
\hline Greece, Ioannina & $\begin{array}{l}\text { Angelopoulos et } \\
\text { al., 2009, } \\
\text { CHILDREN Study } \\
{[36]}\end{array}$ & $\begin{array}{l}\text { BMI, BMI } z \text {-score } \\
\text { (CDC) }\end{array}$ & $\begin{array}{l}\text { dietary intake } \\
\text { (24-hr recall with } \\
\text { interview), PA (q) }\end{array}$ & $\begin{array}{l}\text { BMI, positive, BMI } \\
z \text {-score, no change }\end{array}$ & $\begin{array}{l}\text { MVPA, positive, fruit } \\
\text { intake, positive, SSBs, } \\
\text { positive, and vegetable } \\
\text { intake, no change }\end{array}$ \\
\hline $\begin{array}{l}\text { Netherlands, } \\
\text { Rotterdam }\end{array}$ & $\begin{array}{l}\text { Jansen et al., 2011, } \\
\text { Lekker fit [42] }\end{array}$ & $\begin{array}{l}\text { BMI, BMI-SDS } \\
\text { (IOTF) }\end{array}$ & $\mathrm{X}$ & $\begin{array}{l}\text { BMI, no change, } \\
\text { BMI-SDS, no change }\end{array}$ & $\mathrm{X}$ \\
\hline $\begin{array}{l}\text { New Zealand, } \\
\text { Otago }\end{array}$ & $\begin{array}{l}\text { Taylor et al., 2007, } \\
\text { APPLE [32] }\end{array}$ & $\begin{array}{l}\text { BMI } z \text {-score } \\
(\mathrm{CDC})\end{array}$ & $\begin{array}{l}\text { Dietary intake } \\
\text { (Short Food } \\
\text { Questionnaire), PA } \\
\text { (a), and PA and } \\
\text { television viewing } \\
\text { time (Physical } \\
\text { Activity } \\
\text { Questionnaire for } \\
\text { Older Children) }\end{array}$ & Positive & $\begin{array}{l}\text { Carbonated beverages, } \\
\text { positive, fruit intake, } \\
\text { positive, vegetable intake, } \\
\text { no change, higher } \\
\text { accelerometer counts at } \\
\text { year 1, positive, } \\
\text { accelerometer counts, no } \\
\text { change, PA (q), negative, } \\
\text { and TV viewing time, no } \\
\text { change }\end{array}$ \\
\hline $\begin{array}{l}\text { New Zealand, } \\
\text { Waikato }\end{array}$ & $\begin{array}{l}\text { Rush et al., 2012, } \\
\text { Project Energize } \\
{[43]}\end{array}$ & $\begin{array}{l}\text { BMI-SDS (UK } \\
1990)\end{array}$ & $\mathrm{X}$ & No change & $\mathrm{X}$ \\
\hline Norway, southeast & $\begin{array}{l}\text { Grydeland et al., } \\
\text { 2013, Grydeland et } \\
\text { al., 2014, and Bergh } \\
\text { et al., 2012, HEIA } \\
{[28-30]}\end{array}$ & $\begin{array}{l}\text { BMI, BMI } z \text {-score } \\
(\mathrm{WHO})\end{array}$ & PA (a) & $\begin{array}{l}\text { Total group: BMI, no } \\
\text { change, BMI } z \text {-score, } \\
\text { no change; girls: BMI, } \\
\text { positive, BMI } z \text {-score, } \\
\text { positive; and boys: } \\
\text { BMI, no change, } \\
\text { BMI } z \text {-score, no } \\
\text { change }\end{array}$ & PA, positive \\
\hline Portugal & $\begin{array}{l}\text { Rosário et al., } 2012 \\
\text { [41] }\end{array}$ & BMI & $\begin{array}{l}\text { Dietary intake } \\
\text { (24-hr recall with } \\
\text { interview), PA (q) }\end{array}$ & No change & $\begin{array}{l}\text { Vegetable intake, positive, } \\
\text { fruit intake, positive, and } \\
\text { PA, no change }\end{array}$ \\
\hline
\end{tabular}


TABLE 2: Continued.

\begin{tabular}{|c|c|c|c|c|c|}
\hline Location & $\begin{array}{l}\text { Study ID (author et } \\
\text { al., year, and } \\
\text { intervention name) }\end{array}$ & $\begin{array}{l}\text { Primary measures } \\
\text { (growth reference) }\end{array}$ & $\begin{array}{l}\text { Moderator } \\
\text { variables }\end{array}$ & Primary outcomes & Moderator outcomes \\
\hline $\begin{array}{l}\text { Spain, Reus, } \\
\text { Cambrils, Salou, } \\
\text { and Vila-seca }\end{array}$ & $\begin{array}{l}\text { Tarro et al., 2014, } \\
\text { Education in } \\
\text { Alimentation } \\
\text { (EdAl) [31] }\end{array}$ & $\begin{array}{l}\text { BMI, BMI } z \text {-score } \\
\text { (WHO) }\end{array}$ & $\begin{array}{l}\text { Eating habits } \\
\text { (self-report), } \\
\text { after-school PA (q) }\end{array}$ & $\begin{array}{l}\text { BMI, no change, BMI } \\
z \text {-score, positive }\end{array}$ & $\begin{array}{l}\text { Fruit and vegetable intake, } \\
\text { no change, after-school PA } \\
\text { in participants who } \\
\text { engaged in }>5 \text { hours per } \\
\text { week at baseline, positive }\end{array}$ \\
\hline Spain, Granollers & $\begin{array}{l}\text { Llargues et al., 2011, } \\
\text { Avall [33] }\end{array}$ & BMI & $\begin{array}{l}\text { Eating habits (FFQ } \\
\text { and Krece Plus } \\
\text { test), PA (q) }\end{array}$ & Positive & $\begin{array}{l}\text { fruit intake, positive, } \\
\text { vegetable intake, no change, } \\
\text { SSBs, no change, and PA, } \\
\text { positive }\end{array}$ \\
\hline $\begin{array}{l}\text { United States, } \\
\text { Louisiana }\end{array}$ & $\begin{array}{l}\text { Williamson et al., } \\
\text { 2012, LA Health } \\
\text { Project [34] }\end{array}$ & $\begin{array}{l}\text { BMI } z \text {-score } \\
\text { (CDC) }\end{array}$ & $\begin{array}{l}\text { School food } \\
\text { selection and } \\
\text { intake (digital } \\
\text { photography), PA, } \\
\text { and sedentary time } \\
\text { (Self-Administered } \\
\text { PA Checklist) }\end{array}$ & $\begin{array}{l}\text { PP total: no change; } \\
\text { PP overweight: no } \\
\text { change; PP + SP total: } \\
\text { no change; PP + SP } \\
\text { overweight: no } \\
\text { change; EM total: no } \\
\text { change; EM } \\
\text { overweight: no } \\
\text { change; and EM white } \\
\text { girls: positive }\end{array}$ & $\begin{array}{l}\text { PP: PA, no change, } \\
\text { sedentary time, no change; } \\
\text { PP overweight: PA, } \\
\text { negative; PP + SP: PA, no } \\
\text { change, sedentary time, no } \\
\text { change; PP + SP } \\
\text { overweight: PA, no change; } \\
\text { and EM: PA, no change, } \\
\text { sedentary time, no change }\end{array}$ \\
\hline $\begin{array}{l}\text { United States, } \\
\text { South Dakota }\end{array}$ & $\begin{array}{l}\text { Story et al., 2012, } \\
\text { Bright Start [56] }\end{array}$ & $\begin{array}{l}\text { BMI, BMI } z \text {-score } \\
\text { (CDC) }\end{array}$ & $\mathrm{X}$ & $\begin{array}{l}\text { BMI, no change, BMI } \\
z \text {-score, no change }\end{array}$ & $\mathrm{X}$ \\
\hline
\end{tabular}

$\mathrm{HB}=$ health behaviour.

$\mathrm{HK}=$ health knowledge.

$\mathrm{HA}=$ health attitudes

$\mathrm{a}=$ accelerometer.

$\mathrm{p}=$ pedometer.

$\mathrm{q}=$ questionnaire

$\mathrm{PA}=$ physical activity.

MVPA = moderate vigorous physical activity.

$\mathrm{HE}=$ healthy eating.

SSB $=$ sugar sweetened beverages .

$\mathrm{WHO}=$ World Health Organisation .

IOTF $=$ international obesity task force.

UK 1990 = United Kingdom 1990.

$\mathrm{CDC}=$ center for disease control.

$\mathrm{PP}=$ primary prevention.

$\mathrm{PP}+\mathrm{SP}=$ primary prevention + secondary prevention

$\mathrm{EM}=$ environmental modification

BMI were greater for older children [38], girls [30], and white girls [34], while others found neither sex differences [37] nor weight status differences [34].

3.3. Moderator Variables. Ten studies measured total PA or moderate and vigorous PA (MVPA), and 4 of these studies resulted in improvements in these variables alongside improvement in BMI in the whole intervention group [33, 3537]. Two of the four studies measuring SSB intake reported improved BMI alongside decreased SSB intake $[32,36]$. Eight studies measured fruit and vegetable intake, and three achieved an increase in fruit intake alongside BMI improvement $[32,33,36]$, while no studies resulted in increased vegetable intake alongside BMI improvement. None of the three studies measuring sedentary behaviour $[34,39,40]$ nor the 1 measuring total screen time [32] achieved a decrease in any of these variables. One study that measured weekend and weekday screen time separately achieved a decrease in weekend screen time, no change in weekday screen time, and no change in BMI [40].

3.4. Sustained Intervention Effects. One study reported follow-up measures once the intervention ceased [39]. CHANGE! lasted 5 months and did not achieve a reduction in BMI or BMI $z$-score after measures but reported a significantly lower BMI $z$-score at 10 weeks after intervention.

\section{Discussion}

The findings of the current systematised review suggest that school-based interventions that include HE and PA components are moderately effective methods for improving BMI in elementary school children which is consistent with the findings of others [11, 14]. Similarly, Brown and Summerbell's review suggested that school-based obesity interventions containing $\mathrm{HE}$ and PA components may help 
prevent overweight [11], and Lavelle et al. also determined that school-based interventions may be effective in reducing BMI [14].

Only one study reported age differences [38] and, therefore, no conclusions could be made in terms of effectiveness in different age groups. Two studies found that intervention effectiveness was greater in girls $[30,34]$ which aligned with another review [11], while one study reported no sex differences [37]. Grydeland et al.s [30] and Williamson et al.s [34] findings were consistent with Brown and Summerbell's [11] conclusions of obesity interventions being more effective in girls. These findings may be due to the diverse nature of intervention approaches as Grydeland et al. [30] noted in the Health in Adolescents (HEIA) programme that the developers, implementers, and teachers involved were primarily women which may have unintentionally biased components towards girls. Gender bias has also been suggested by Befort who noted that since the 1980s adult obesity interventions may have been unintentionally favoured towards women [44]. Although limited evidence is available which suggests this is apparent in youth interventions, it is recommended that future work examine the potential for gender bias.

Moderators for BMI improvement included increased PA, lowered SSB intake, and increased fruit intake. The studies in this review that measured sedentary behaviour and screen time did not result in reductions in these behaviours or improvements in BMI. This is in contrast to DeMattia and colleagues' review that found that two of the three included elementary school studies were effective in reducing sedentary behaviours with one noting improvements in BMI [45]. The studies that were effective in reducing sedentary behaviours in the previously mentioned review intensively implemented techniques specific to reducing sedentary behaviour. It may be that school-based interventions with broader aims at improving multiple behaviours may not be intensive enough to reduce sedentary time. Nonetheless, further work is needed in order to identify ways to improve these variables.

PA and/or MVPA was the most reported moderator with six studies using objective measures (accelerometer or pedometer) and five studies using questionnaires. In those studies that captured objectively measured PA, three studies demonstrated improvements in PA alongside improvements in BMI. Reduction of SSB intake has been reported by parents and children to be one of the easiest health behaviours to modify [46] and it is encouraging that two out of four studies that measured SSB intake reported improvements in BMI alongside a decrease in SSB intake. A systematic review determined a positive association between SSB intake and obesity in children [47]. The link may be due to the high sugar content and low satiety associated with SSBs. Lowering SSB intake may be achievable through school-based initiatives and may help improve BMI.

None of the studies measuring vegetable intake increased this variable alongside BMI improvement. Increasing vegetable consumption appeared more difficult than increasing fruit intake which may be attributed to the child's perception of fruit being more palatable than vegetables [48].

Teachers play a strong role in a child's social environment and have the potential to positively influence behaviours through environmental and social interactions [49]. Teacherled interventions were effective in improving BMI. They were also the most common delivery method and may be the most sustainable approach for long-term impact.

Multiple reviews have stressed the importance of basing child obesity interventions on behaviour change theories $[27,50,51]$. However, the improvement of BMI in this study did not seem to be impacted by the use of any theoretical approach. It may be that some researchers in this study used strategies based on behaviour change theories but failed to report the theoretical framework. The popular use of SCT was consistent with school-based interventions from 1999 to 2004 [50].

It was unclear how parental involvement influenced intervention effectiveness given the disparity between levels of parental involvement across studies. Six of the eleven studies that included a parental involvement component resulted in BMI improvement; however, three of the four studies that did not include a parental involvement component within their study design also reported improvements in BMI. These findings are in line with Cook-Cottone and colleagues review which found that interventions with minimal or moderate degrees of parental involvement achieved similar BMI results to those without a parental involvement component [21]. Additionally, other reviews have found that the degree of intervention effectiveness is related to the extent of parental involvement implemented [52, 53]. Although minimal parental involvement may be viewed as a more sustainable teacher-led method, more intensive efforts could increase intervention effectiveness.

While multiple combinations of environmental, educational, and physical strategies demonstrated the capacity to improve child BMI, education-only interventions may not be sufficient to induce behaviour change. In line with SCT, our findings suggest that if a child's environment does not support and reinforce new knowledge and attitudes from education and/or the child does not practice the new PA knowledge through performing PA in a supportive environment, the likelihood of inducing behaviour change may be low [54]. Long-term interventions that seek to increase PA and improve HE through behaviours such as decreasing SSB intake and increasing fruit intake through a combination of environmental, educational, and physical strategies may be effective in improving BMI.

A number of limitations must be considered. Methodological limitations included the absence of quantitative assessment, use of one reviewer, and the use of BMI as an obesity marker. Although a qualitative review by one reviewer limited the type of conclusions that could be drawn, this review's focused approach allowed for a detailed synthesis of the most widely used obesity indicator in school-based interventions. Additionally, the use of other obesity measures such as waist circumference, body fat $\%$, or waist-to-height ratio may give a better representation of child disease risk [55].

Methodological limitations of studies included a lack of reporting of adverse events, reporting characteristics of participants lost to follow-up, blinding subjects and assessors to conditions, measuring intervention fidelity, concealing 
intervention assignment from schools, reporting if participants who agreed to take part were representative of the population, and taking participants lost to follow-up into account. Thorough reporting procedures and the control for biases that threaten internal validity will allow the reader to make a fair judgment of study findings. Although great effort is required to carry out high-quality studies in school-based interventions, it is possible that publication bias in terms of researchers not reporting negative findings in studies may have influenced the results of this review.

\section{Conclusions}

Findings from this systematised review suggest that longterm initiatives that include a parental component and involve multiple environmental, educational, and physical strategies may be the most promising for improving indices of adiposity in elementary school aged children. Future schoolbased interventions designed to improve children's weight status should focus efforts to increase PA, decrease sedentary behaviours, lower SSB intake, and increase fruit intake, as well as BMI improvement. Targeted moderators could include increasing PA, lowering SSB intake, and increasing fruit intake. Although it is unlikely that one specific school-based intervention can be effective across different cultures, the identification of these moderators that have demonstrated promise should be incorporated into future efforts in combating the perpetuation of child obesity.

\section{Competing Interests}

The authors declare that they have no competing interests.

\section{References}

[1] M. Ng, T. Fleming, M. Robinson et al., "Global, regional, and national prevalence of overweight and obesity in children and adults during 1980-2013: a systematic analysis for the Global Burden of Disease study 2013," The Lancet, vol. 384, no. 9945, pp. 766-781, 2014.

[2] K. S. de Silva, V. P. Wickramasinghe, and I. N. Gooneratne, "Metabolic consequences of childhood obesity-a preliminary report," The Ceylon Medical Journal, vol. 51, no. 3, pp. 105-109, 2006.

[3] D. S. Freedman, L. K. Khan, W. H. Dietz, S. R. Srinivasan, and G. S. Berenson, "Relationship of childhood obesity to coronary heart disease risk factors in adulthood: The Bogalusa Heart Study," Pediatrics, vol. 108, no. 3, pp. 712-718, 2001.

[4] T. J. Cole, M. C. Bellizzi, K. M. Flegal, and W. H. Dietz, "Establishing a standard definition for child overweight and obesity worldwide: international survey," British Medical Journal, vol. 320, no. 7244, pp. 1240-1243, 2000.

[5] T. J. Cole, J. V. Freeman, and M. A. Preece, "Body mass index reference curves for the UK, 1990," Archives of Disease in Childhood, vol. 73, no. 1, pp. 25-29, 1995.

[6] M. de Onis, A. W. Onyango, E. Borghi, A. Siyam, C. Nishida, and J. Siekmann, "Development of a WHO growth reference for school-aged children and adolescents," Bulletin of the World Health Organization, vol. 85, no. 9, pp. 660-667, 2007.
[7] R. J. Kuczmarski, C. L. Ogden, L. M. Grummer-Strawn et al., "CDC growth charts: United States", Advance Data, vol. 314, pp. $1-27,2000$.

[8] T. J. Cole, J. V. Freeman, and M. A. Preece, "British 1990 growth reference centiles for weight, height, body mass index and head circumference fitted by maximum penalized likelihood," Statistics in Medicine, vol. 17, no. 4, pp. 407-429, 1998.

[9] World Health Organization, Obesity: Preventing and Managing the Global Epidemic: Report of a WHO Consultation on Obesity, WHO, Geneva, Switzerland, 2000.

[10] Committee on Physical Activity and Physical Education in the School Environment, Educating the Student Body: Taking Physical Activity and Physical Education to School, Institute of Medicine of the National Academies, 2013.

[11] T. Brown and C. Summerbell, "Systematic review of schoolbased interventions that focus on changing dietary intake and physical activity levels to prevent childhood obesity: an update to the obesity guidance produced by the National Institute for Health and Clinical Excellence," Obesity Reviews, vol. 10, no. 1, pp. 110-141, 2009.

[12] C. Gonzalez-Suarez, A. Worley, K. Grimmer-Somers, and V. Dones, "School-based interventions on childhood obesity: a meta-analysis," American Journal of Preventive Medicine, vol. 37, no. 5, pp. 418-427, 2009.

[13] L.-S. Hung, D. K. Tidwell, M. E. Hall, M. L. Lee, C. A. Briley, and B. P. Hunt, "A meta-analysis of school-based obesity prevention programs demonstrates limited efficacy of decreasing childhood obesity," Nutrition Research, vol. 35, no. 3, pp. 229240, 2015.

[14] H. V. Lavelle, D. F. Mackay, and J. P. Pell, "Systematic review and meta-analysis of school-based interventions to reduce body mass index," Journal of Public Health, vol. 34, no. 3, pp. 360-369, 2012.

[15] J. P. T. Higgins and S. Green, Cochrane Handbook for Systematic Reviews and Interventions, Edited by T.C. Collaboration, 2011, http://handbook.cochrane.org/.

[16] M. J. Grant and A. Booth, "A typology of reviews: an analysis of 14 review types and associated methodologies," Health Information and Libraries Journal, vol. 26, no. 2, pp. 91-108, 2009.

[17] D. Moher, A. Liberati, J. Tetzlaff, and D. G. Altman, "Preferred reporting items for systematic reviews and meta-analyses: the PRISMA statement," Journal of Clinical Epidemiology, vol. 62, no. 10, pp. 1006-1012, 2009.

[18] R. Kersh and J. Morone, "The politics of obesity: seven steps to government action," Health Affairs, vol. 21, no. 6, pp. 142-153, 2002.

[19] S. E. Taverno Ross, M. Dowda, N. Colabianchi, R. Saunders, and R. R. Pate, "After-school setting, physical activity, and sedentary behavior in 5th grade boys and girls," Health and Place, vol. 18, no. 5, pp. 951-955, 2012.

[20] F. T. Shaya, D. Flores, C. M. Gbarayor, and J. Wang, "Schoolbased obesity interventions: a literature review," Journal of School Health, vol. 78, no. 4, pp. 189-196, 2008.

[21] C. Cook-Cottone, C. M. Casey, T. H. Feeley, and J. baran, "A meta-analytic review of obesity prevention in the schools: 19972008," Psychology in the Schools, vol. 46, no. 8, pp. 695-719, 2009.

[22] W. Zenzen and S. Kridli, "Integrative review of school-based childhood obesity prevention programs," Journal of Pediatric Health Care, vol. 23, no. 4, pp. 242-258, 2009. 
[23] Y. Demetriou and O. Höner, "Physical activity interventions in the school setting: a systematic review," Psychology of Sport and Exercise, vol. 13, no. 2, pp. 186-196, 2012.

[24] S. H. Downs and N. Black, "The feasibility of creating a checklist for the assessment of the methodological quality both of randomised and non-randomised studies of health care interventions," Journal of Epidemiology and Community Health, vol. 52, no. 6, pp. 377-384, 1998.

[25] K. Marquet, A. Liesenborgs, J. Bergs, A. Vleugels, and N. Claes, "Incidence and outcome of inappropriate in-hospital empiric antibiotics for severe infection: a systematic review and metaanalysis," Critical Care, vol. 19, no. 1, article 63, pp. 1-12, 2015.

[26] T. HaiBo, K. Xin, L. ShiHeng, and L. Lin, "Comparison of Ahmed glaucoma valve implantation and trabeculectomy for glaucoma: a systematic review and meta-analysis," PLoS ONE, vol. 10, no. 2, Article ID e0118142, 2015.

[27] R. K. Golley, G. A. Hendrie, A. Slater, and N. Corsini, "Interventions that involve parents to improve children's weight-related nutrition intake and activity patterns - what nutrition and activity targets and behaviour change techniques are associated with intervention effectiveness?" Obesity Reviews, vol. 12, no. 2, pp. 114-130, 2011.

[28] I. H. Bergh, M. Bjelland, M. Grydeland et al., "Mid-way and post-intervention effects on potential determinants of physical activity and sedentary behavior, results of the HEIA studya multi-component school-based randomized trial," International Journal of Behavioral Nutrition and Physical Activity, vol. 9, article 63, 2012.

[29] M. Grydeland, I. H. Bergh, M. Bjelland et al., "Intervention effects on physical activity: the HEIA study-a cluster randomized controlled trial," International Journal of Behavioral Nutrition and Physical Activity, vol. 10, article 17, 2013.

[30] M. Grydeland, M. Bjelland, S. A. Anderssen et al., "Effects of a 20-month cluster randomised controlled school-based intervention trial on BMI of school-aged boys and girls: the HEIA study," British Journal of Sports Medicine, vol. 48, no. 9, pp. 768-773, 2014.

[31] L. Tarro, E. Llauradó, R. Albaladejo et al., "A primary-schoolbased study to reduce the prevalence of childhood obesitythe EdAl (Educació en Alimentació) study: a randomized controlled trial," Trials, vol. 15, article 58, 2014.

[32] R. W. Taylor, K. A. McAuley, W. Barbezat, A. Strong, S. M. Williams, and J. I. Mann, "APPLE project: 2-y findings of a community-based obesity prevention program in primary school-age children," American Journal of Clinical Nutrition, vol. 86, no. 3, pp. 735-742, 2007.

[33] E. Llargues, R. Franco, A. Recasens et al., "Assessment of a school-based intervention in eating habits and physical activity in school children: the AVall study," Journal of Epidemiology and Community Health, vol. 65, no. 10, pp. 896-901, 2011.

[34] D. A. Williamson, C. M. Champagne, D. W. Harsha et al., "Effect of an environmental school-based obesity prevention program on changes in body fat and body weight: a randomized trial," Obesity, vol. 20, no. 8, pp. 1653-1661, 2012.

[35] T. Gorely, M. E. Nevill, J. G. Morris, D. J. Stensel, and A. Nevill, "Effect of a school-based intervention to promote healthy lifestyles in 7-11 year old children," International Journal of Behavioral Nutrition and Physical Activity, vol. 6, article 5, 2009.

[36] P. D. Angelopoulos, H. J. Milionis, E. Grammatikaki, G. Moschonis, and Y. Manios, "Changes in BMI and blood pressure after a school based intervention: the CHILDREN study,"
European Journal of Public Health, vol. 19, no. 3, pp. 319-325, 2009.

[37] J. Kain, F. Concha, L. Moreno, and B. Leyton, "School-based obesity prevention intervention in Chilean children: effective in controlling, but not reducing obesity," Journal of Obesity, vol. 2014, Article ID 618293, 8 pages, 2014.

[38] S. Stock, C. Miranda, S. Evans et al., "Healthy Buddies: a novel, peer-led health promotion program for the prevention of obesity and eating disorders in children in elementary school," Pediatrics, vol. 120, no. 4, pp. e1059-e1068, 2007.

[39] S. J. Fairclough, A. F. Hackett, I. G. Davies et al., "Promoting healthy weight in primary school children through physical activity and nutrition education: a pragmatic evaluation of the CHANGE! randomised intervention study," BMC Public Health, vol. 13, no. 1, article 626, 2013.

[40] R. R. Kipping, L. D. Howe, R. Jago et al., "Effect of intervention aimed at increasing physical activity, reducing sedentary behaviour, and increasing fruit and vegetable consumption in children: Active for Life Year 5 (AFLY5) school based cluster randomised controlled trial," British Medical Journal, vol. 348, Article ID g3256, 2014.

[41] R. Rosário, B. Oliveira, A. Araújo et al., "The impact of an intervention taught by trained teachers on childhood overweight," International Journal of Environmental Research and Public Health, vol. 9, no. 4, pp. 1355-1367, 2012.

[42] W. Jansen, H. Raat, E. J.-V. Zwanenburg, I. Reuvers, R. Van Walsem, and J. Brug, "A school-based intervention to reduce overweight and inactivity in children aged 6-12 years: study design of a randomized controlled trial," BMC Public Health, vol. 8, article 257, 2008.

[43] E. Rush, P. Reed, S. McLennan, T. Coppinger, D. Simmons, and D. Graham, "A school-based obesity control programme: project energize. Two-year outcomes," British Journal of Nutrition, vol. 107, no. 4, pp. 581-587, 2012.

[44] C. Befort, "Bridging the gender gap in behavioral obesity intervention: a comment on Morgan et al," Annals of Behavioral Medicine, vol. 45, no. 2, pp. 133-134, 2013.

[45] L. DeMattia, L. Lemont, and L. Meurer, "Do interventions to limit sedentary behaviours change behaviour and reduce childhood obesity? A critical review of the literature," Obesity Reviews, vol. 8, no. 1, pp. 69-81, 2007.

[46] S. M. Looney and H. A. Raynor, "Examining the effect of three low-intensity pediatric obesity interventions: a pilot randomized controlled trial," Clinical Pediatrics, vol. 53, no. 14, pp. 13671374, 2014.

[47] V. S. Malik, M. B. Schulze, and F. B. Hu, "Intake of sugarsweetened beverages and weight gain: a systematic review," American Journal of Clinical Nutrition, vol. 84, no. 2, pp. 274288, 2006.

[48] L. Blanchette and J. Brug, "Determinants of fruit and vegetable consumption among 6-12-year-old children and effective interventions to increase consumption," Journal of Human Nutrition and Dietetics, vol. 18, no. 6, pp. 431-443, 2005.

[49] J. S. Gubbels, S. P. J. Kremers, D. H. H. van Kann et al., "Interaction between physical environment, social environment, and child characteristics in determining physical activity at child care," Health Psychology, vol. 30, no. 1, pp. 84-90, 2011.

[50] M. Sharma, "School-based interventions for childhood and adolescent obesity," Obesity Reviews, vol. 7, no. 3, pp. 261-269, 2006.

[51] C. A. Nixon, H. J. Moore, W. Douthwaite et al., "Identifying effective behavioural models and behaviour change strategies 
underpinning preschool- and school-based obesity prevention interventions aimed at 4-6-year-olds: a systematic review," Obesity Reviews, vol. 13, supplement 1, pp. 106-117, 2012.

[52] W. Van Lippevelde, M. Verloigne, I. De Bourdeaudhuij et al., "Does parental involvement make a difference in school-based nutrition and physical activity interventions? A systematic review of randomized controlled trials," International Journal of Public Health, vol. 57, no. 4, pp. 673-678, 2012.

[53] J. J. Van Der Kruk, F. Kortekaas, C. Lucas, and H. JagerWittenaar, "Obesity: a systematic review on parental involvement in long-term European childhood weight control interventions with a nutritional focus," Obesity Reviews, vol. 14, no. 9, pp. 745-760, 2013.

[54] A. Bandura, "Social cognitive theory: an agentic perspective," Annual Review of Psychology, vol. 52, pp. 1-26, 2001.

[55] A. Bosy-Westphal, C. Geisler, S. Onur et al., "Value of body fat mass vs anthropometric obesity indices in the assessment of metabolic risk factors," International Journal of Obesity, vol. 30, no. 3, pp. 475-483, 2006.

[56] M. Story, P. J. Hannan, J. A. Fulkerson et al., "Bright start: description and main outcomes from a group-randomized obesity prevention trial in American Indian children," Obesity, vol. 20, no. 11, pp. 2241-2249, 2012. 


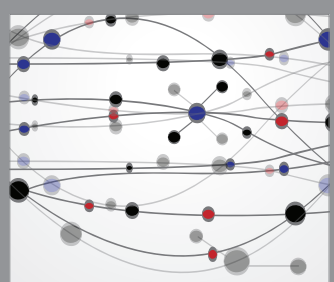

The Scientific World Journal
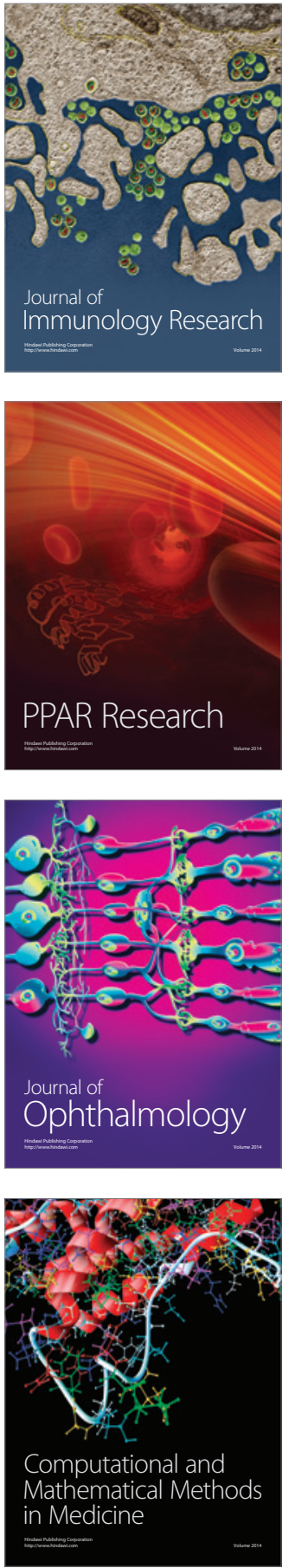

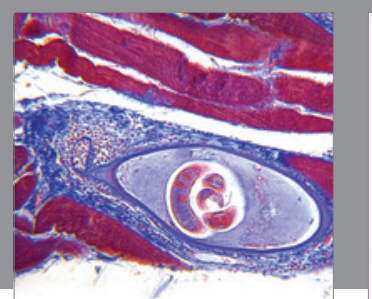

Gastroenterology Research and Practice

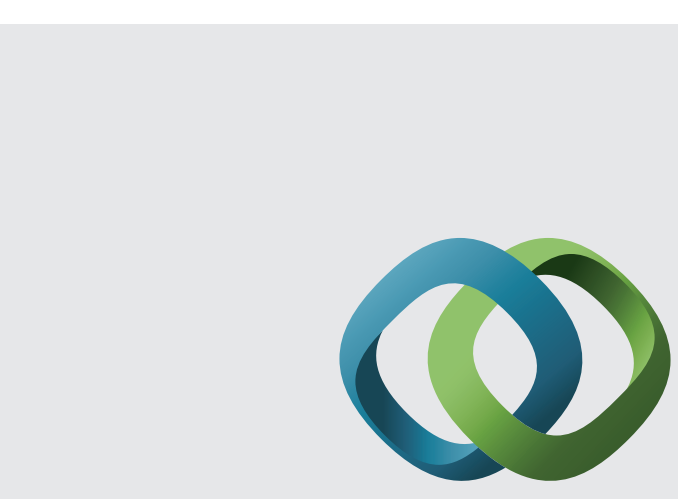

\section{Hindawi}

Submit your manuscripts at

http://www.hindawi.com
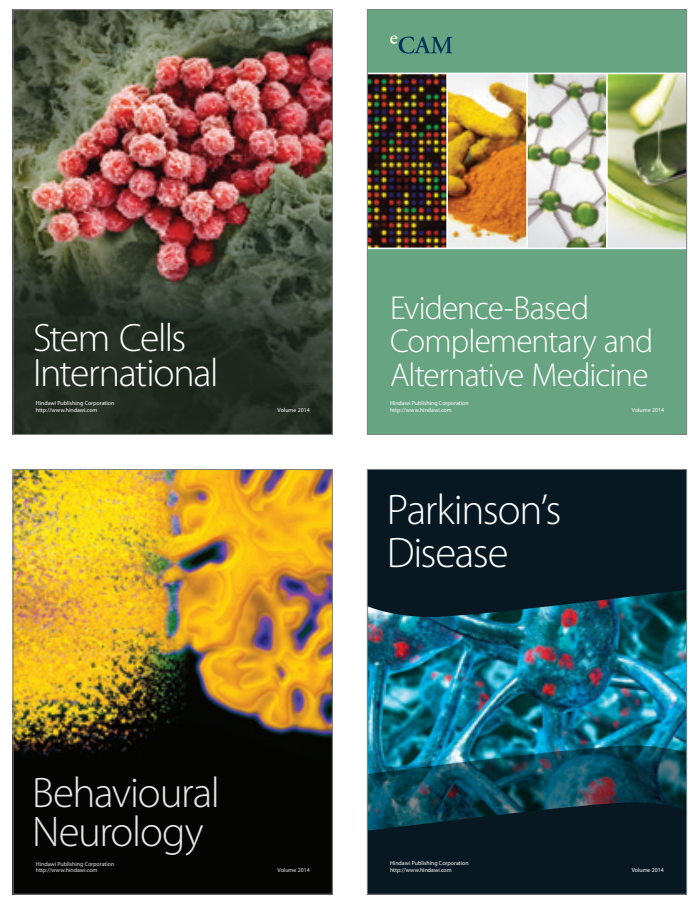
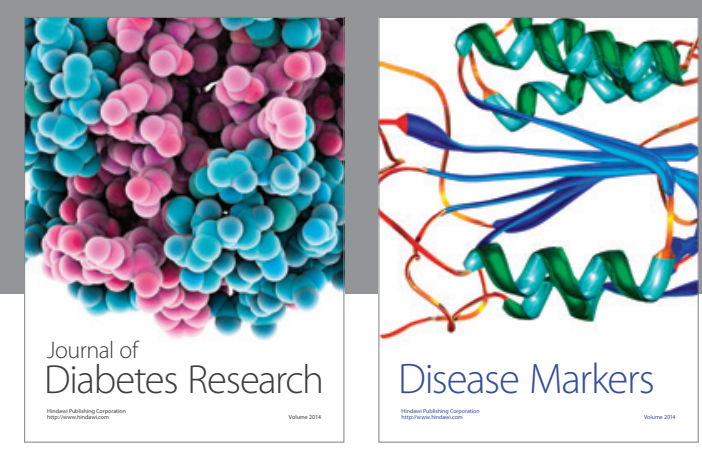

Disease Markers
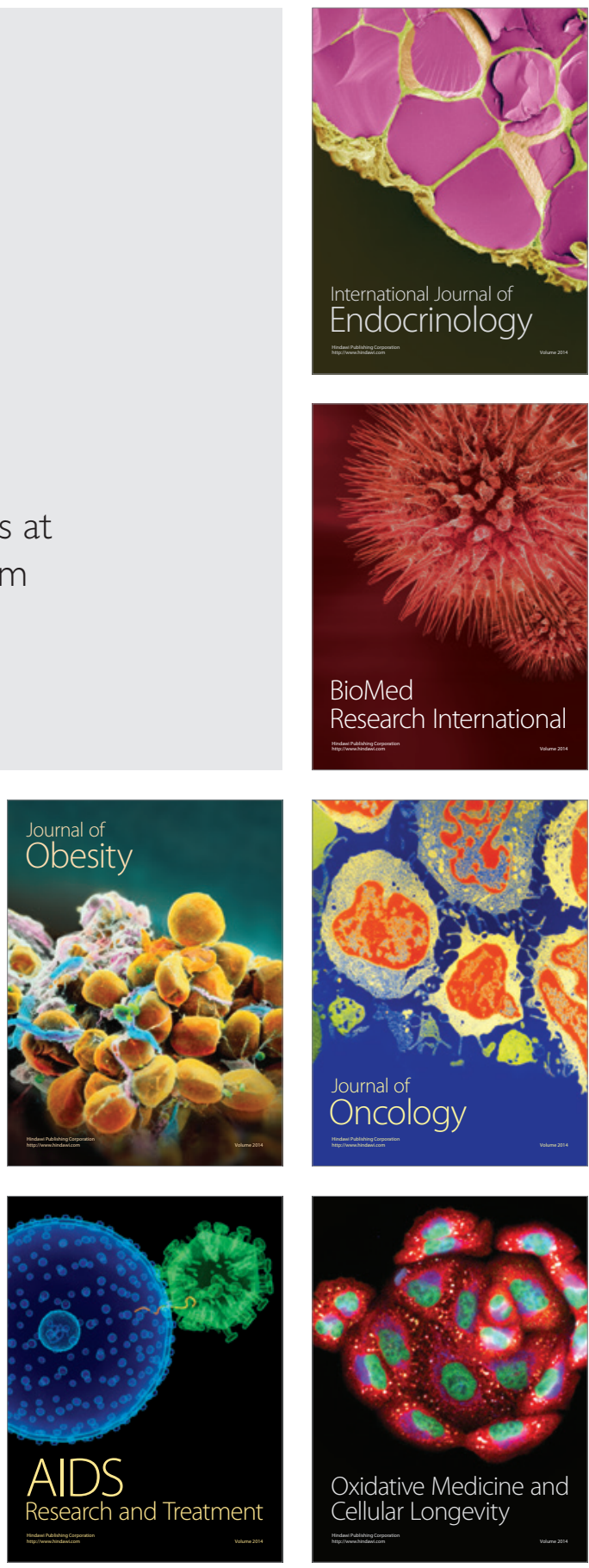